\title{
Colloidal Stability of Emulsifier-free Triolein-in-Water Emulsions: Effects of Temperature
}

\author{
Kazuo Takei ${ }^{1,2}$, Masaru Watanabe ${ }^{3}$, Keita Kawasaki ${ }^{3}$, and Toshio Sakai ${ }^{2,3,4 *}$ \\ ${ }^{1}$ Tokyo Food Co., Ltd., 1687-1 Kamioshima, Tsukuba, Ibaraki 300-4351, JAPAN \\ ${ }^{2}$ Graduate School of Medicine, Science and Technology, Shinshu University, 4-17-1 Wakasato, Nagano 380-8553, JAPAN \\ ${ }^{3}$ Graduate School of Science and Technology, Shinshu University, 4-17-1 Wakasato, Nagano 380-8553, JAPAN \\ ${ }^{4}$ Department of Materials Chemistry, Faculty of Engineering, Shinshu University, 4-17-1 Wakasato, Nagano 380-8553, JAPAN
}

\begin{abstract}
Herein, we report the colloidal stability of emulsifier-free (EF-) triolein-in-water (TO/W) emulsions prepared by mixing TO and water using a high-powered bath-type ultrasonicator (HPBath-US; $28 \mathrm{kHz}, 300 \mathrm{~W}$ ) in the absence of emulsifiers such as surfactants. In particular, the effect of the temperature $\left(15-60^{\circ} \mathrm{C}\right)$ on the colloidal stability of $\mathrm{EF}-\mathrm{TO} / \mathrm{W}$ emulsions was examined because this is important for the practical application of EF-TO/W emulsions, for example, in foods, pharmaceuticals, and cosmetics. We found that the colloidal stability of the EF-TO/W emulsions decreased with increase in the temperature from 15 to $25^{\circ} \mathrm{C}$, whereas it increased with increase in temperature from 25 to $40^{\circ} \mathrm{C}$, and the high colloidal stability of the EF-TO/W emulsions was maintained above $40^{\circ} \mathrm{C}$. The reduction in the colloidal stability of EF-TO/W emulsions between 15 and $25^{\circ} \mathrm{C}$ is likely a result of the TO droplets formed by thermal motion, as well as enhanced Ostwald ripening at higher temperatures. On the other hand, the increase in the colloidal stability of the EF-TO/W emulsions from 25 to $40^{\circ} \mathrm{C}$ and their high colloidal stability above $40^{\circ} \mathrm{C}$ is attributed to the reduction in the interfacial tension between TO and water at higher temperatures. This decrease in the interfacial tension between $\mathrm{TO}$ and water with temperature increase is related to the transformation of short-range ordered domains (clusters) of TO molecules in the liquid state, which increases the colloidal stability of the EF-TO/W emulsions.
\end{abstract}

Key words: emulsifier-free triolein-in-water emulsion, colloidal stability, temperature, interfacial free energy, short-range ordered domain

\section{Introduction}

Oil-in-water (O/W) and water-in-oil (W/O) emulsions are used in various products and manufacturing processes in a broad range of industries, including the food, cosmetics, pharmaceutical, agrochemical, paint, and oil industries ${ }^{1-3)}$. This popularity is a result of the unique properties of emulsions afforded by the liquid droplets (dispersed phase), continuous phase, and interface between oil and water phases. Typically, the preparation and stabilization of emulsions require emulsifiers, such as surfactants or amphiphilic polymers. However, in recent years, emulsifier-free (EF-) emulsion products, which are prepared in the absence of any emulsifiers, have become in-demand because of the rise in green products and green manufacturing ${ }^{4-25}$. For example, in the food industry in the last few years, the "clean label" concept has become popular because consumers increasingly prefer the use of natural, safe, and sustainable materials, and as a result, many manufacturers have focused on the development of EF-products ${ }^{26-28)}$. Therefore, it is important to understand the fundamental nature of EF-emulsions: for example, the effect of the oil properties and the effects of the preparation and storage temperature on the colloidal stability of EF-O/W and EF-W/ $\mathrm{O}$ emulsions. Therefore, we have previously investigated the effects of the oil properties on the colloidal stability of $\mathrm{EF}-\mathrm{O} / \mathrm{W}$ and EF-W/O emulsions to evaluate the fundamentals of the colloidal stabilization of emulsions ${ }^{4-16)}$.

In contrast, in this work, the effect of the preparation and storage temperatures on the colloidal stability of EFtriolein-in-water (EF-TO/W) emulsions was examined because triolein $(\mathrm{TO})$ is a typical triacylglycerol $(\mathrm{TG})$ that is frequently used in foods, pharmaceuticals, and cosmetic products, and temperature is one of the most important parameters affecting the manufacture and storage of emul-

\footnotetext{
*Correspondence to: Toshio Sakai, Graduate School of Medicine, Science and Technology, Shinshu University, 4-17-1 Wakasato, Nagano 380-8553, JAPAN

E-mail: tsakai@shinshu-u.ac.jp

Accepted September 22, 2021 (received for review July 17, 2021)

Journal of Oleo Science ISSN 1345-8957 print / ISSN 1347-3352 online

http://www.jstage.jst.go.jp/browse/jos/ http://mc.manusriptcentral.com/jjocs

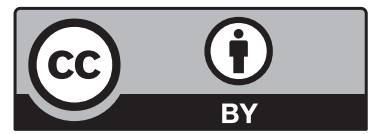




\section{K. Takei, M. Watanabe, K. Kawasaki et al.}

sion-based products.

\section{Experimental}

\subsection{Preparation of EF-TO/W emulsions}

EF-TO/W emulsions were prepared by mixing $0.1 \mathrm{~mL}$ of $\mathrm{TO}\left(\mathrm{C}_{57} \mathrm{H}_{104} \mathrm{O}_{6},>99 \%\right.$, Merck KGaA $)$ and $25 \mathrm{~mL}$ of ultrapure water $\left(18.2 \mathrm{M} \Omega \mathrm{cm}\right.$ at $25^{\circ} \mathrm{C}$, Millipore-filtered water) using a high-powered bath-type ultrasonicator (HPBath-US; 28 $\mathrm{kHz}, 300 \mathrm{~W})$ for $5 \mathrm{~min}$ at $15,20,25,30,35,40,50$, and $60^{\circ} \mathrm{C}$.

\subsection{Characterization of colloidal stability of EF-TO/W emulsions}

The colloidal stabilities of the prepared EF-TO/W emulsions were characterized by monitoring the turbidity of the EF-TO/W emulsions with time from the moment of preparation. For this, the prepared EF-TO/W emulsions were stored at $15,20,25,30,35,40,50$, and $60^{\circ} \mathrm{C}$. The turbidity of the EF-TO/W emulsion was obtained from the difference between the transmittances of the continuous phase (water phase) and EF-TO/W emulsion at a wavelength of $700 \mathrm{~nm}$, as measured with a UV-visible spectrophotometer (V-630, JASCO). The change in the turbidity of the EF-TO/W emulsion with elapsed time is caused by the creaming (floating) of TO droplets in the EF-TO/W emulsion because the light used for the turbidity measurement passes through a window positioned $5.0 \mathrm{~mm}$ from the bottom of the glass cuvette, i.e., far from the location of the separated oil.

\subsection{Characterization of the diameter and zeta potential of TO droplets in EF-TO/W emulsions, densities of wa- ter and TO, and interfacial tension between TO and water}

The diameter and zeta potential of TO droplets in the EF-TO/W emulsions prepared at 15, 20, 25, 30, 35 40, 50, and $60^{\circ} \mathrm{C}$ were measured at the same temperatures as the preparation temperatures using laser diffraction(LA-950, HORIBA) and electrophoretic light scattering (Zetasizer Nano, Malvern), respectively. The densities of water and TO at $15,20,25,30,35,40,50$, and $60^{\circ} \mathrm{C}$ were measured with a standard specific gravity meter (19-4, AS ONE). The interfacial tension $(\gamma)$ values between $\mathrm{TO}$ and water at 15 , $20,25,30,35,40,50$, and $60^{\circ} \mathrm{C}$ were measured using the Wilhelmy method (CBVP-A3, Kyowa Interface Science Co., Ltd.).

\section{Results and Discussion}

The white color of the EF-TO/W emulsions prepared and stored at 15,20 , and $35^{\circ} \mathrm{C}$ gradually became light white
Temperature $\left({ }^{\circ} \mathrm{C}\right)$

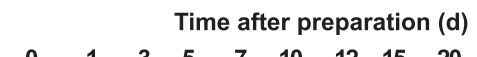

$\begin{array}{lllllllllll}0 & 1 & 3 & 5 & 7 & 10 & 12 & 15 & 20 & 25 & 30\end{array}$

15

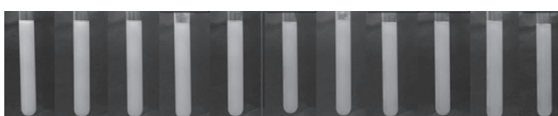

20

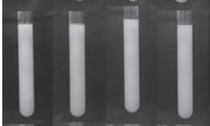

1

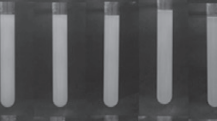

25
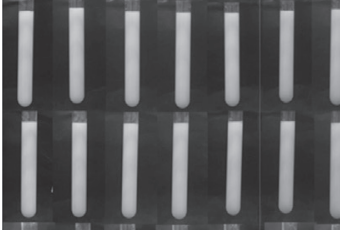

1

30

35
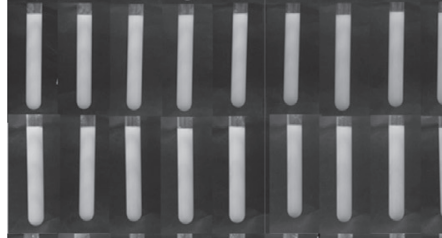

11

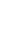

35

40

50

60

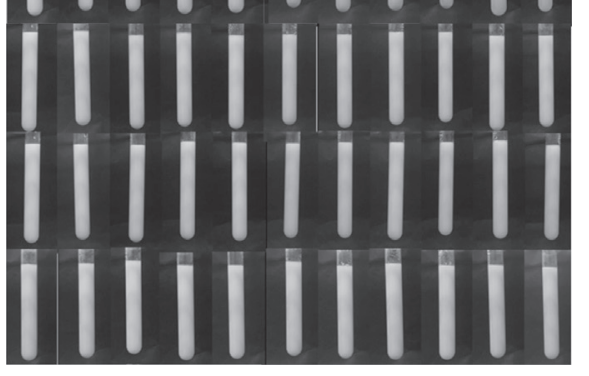

Fig. 1 EF-TO/W emulsions observed with elapsed time after preparation at $15,20,25,30,35,40,50$ and $60^{\circ} \mathrm{C}$.

over $30 \mathrm{~d}$ after preparation(see Fig. 1). In the case of the EF-TO/W emulsions prepared and stored at 25 and $30^{\circ} \mathrm{C}$, the creaming of oil droplets was observed over $30 \mathrm{~d}$ after preparation, in which the white color of the EF-TO/W emulsions moved to the upper region and the bottom of the vessel became light white (see Fig. 1). No significant changes over 30 days after preparation were observed for the EF-TO/W emulsions prepared and stored between 40 and $60^{\circ} \mathrm{C}$ (see Fig. 1). The turbidities of the EF-TO/W emulsions prepared and stored at 15,20 , and $35^{\circ} \mathrm{C}$ slightly decreased with time after preparation (see plot markers $\bigcirc$, and $\triangle$ in Fig. 2). The turbidities of the EF-TO/W emulsions prepared and stored at 25 and $30^{\circ} \mathrm{C}$ decreased with time after preparation(see plot markers $\square$ and $\boldsymbol{\square}$ in Fig. 2). On the other hand, the turbidities of the EF-TO/W emulsions prepared and stored between 40 and $60^{\circ} \mathrm{C}$ showed negligible changes over $30 \mathrm{~d}$ after preparation (see plot markers $\boldsymbol{\Delta}, \nabla$ and $\boldsymbol{\nabla}$ in Fig. 2). The turbidity values of the EF-TO/W emulsions measured $20 \mathrm{~d}$ after preparation and plotted as a function of preparation and storage temperature decreased and increased as the temperature was increased from 15 to $25^{\circ} \mathrm{C}$ and from 25 to $40^{\circ} \mathrm{C}$, respectively, but plateaued above $40^{\circ} \mathrm{C}$ (see Fig. 3). That is, the colloidal stabilities of the EF-TO/W emulsions decreased in the lower temperature range and increased in the midtemperature range. The decrease in the colloidal stability 


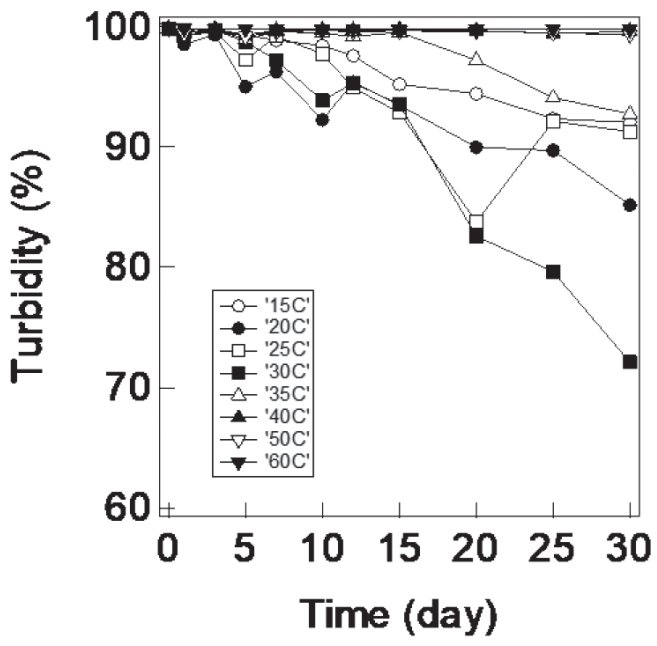

Fig. 2 Turbidity of EF-TO/W emulsions recorded with elapsed time after preparation at $(\bigcirc) 15,(\bigcirc) 20$,

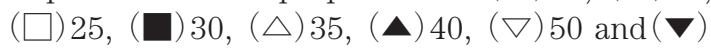
$60^{\circ} \mathrm{C}$.

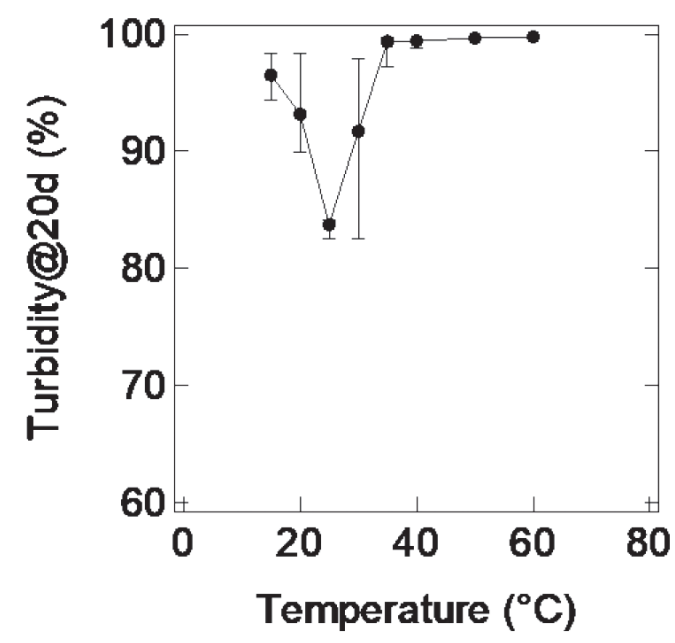

Fig. 3 ( Turbidity of EF-TO/W emulsions measured at 20 d after preparation plotted as a function of temperature. Plot represents average turbidity of EF-TO/W emulsions measured at $20 \mathrm{~d}$ after preparation, and error bar represents the minimum and maximum of turbidity of EF-TO/W emulsions in each measurement ( 3 times) at $20 \mathrm{~d}$ after preparation.

of the EF-TO/W emulsions between 15 and $25^{\circ} \mathrm{C}$ can be attributed to the enhanced merging of TO droplets, as well as increased Ostwald ripening, with increasing temperature, which is common temperature-dependent behavior of O/W emulsions. For comparison, Fig. S1 shows the turbidity of EF-dodecane-in-water (DD/W) emulsion and EF-hexadecane-in-water (HD/W) emulsions measured 5 d after preparation and plotted as a function of preparation and storage temperatures. As shown, over $5 \mathrm{~d}$, the turbidity values of the EF-DD/W and EF-HD/W emulsions decreased with increase in temperature from 15 to $60^{\circ} \mathrm{C}$. This result indicates that the colloidal stability of the EF-TO/W emulsions on increase in temperature from 25 to $40^{\circ} \mathrm{C}$ and the high colloidal stability of EF-TO/W emulsions above $40^{\circ} \mathrm{C}$ is a unique feature of $\mathrm{O} / \mathrm{W}$ emulsions.

First, the effect of creaming on the colloidal stability of EF-TO/W emulsions was examined to evaluate the mechanism of the increase in the colloidal stability of EF-TO/W emulsions on increase in temperature from 25 to $40^{\circ} \mathrm{C}$. Generally, O/W emulsions are demulsified through creaming, which involves the floating of oil droplets in O/W emulsions or the sedimentation of water droplets in W/O emulsions. The creaming of $\mathrm{O} / \mathrm{W}$ emulsions is expressed by Stokes' law (Eq. 1) ${ }^{29)}$.

$$
u=\frac{2 r^{2}\left(\rho_{0}-\rho\right) g}{9 \eta}
$$

Here, $u(\mathrm{~m} / \mathrm{s})$ is the floating velocity of oil droplets in an O/W emulsion, $r(\mathrm{~m})$ is the radius of the oil droplets, $g(\mathrm{~m} /$ $\left.\mathrm{s}^{2}\right)$ is gravitational acceleration, $\rho_{0}\left(\mathrm{~kg} / \mathrm{m}^{3}\right)$ is the mass density of water (continuous phase), $\rho\left(\mathrm{kg} / \mathrm{m}^{3}\right)$ is the mass density of oil (dispersed phase), and $\eta(\mathrm{Pa} \mathrm{s}=\mathrm{kg} / \mathrm{m} \cdot \mathrm{s})$ is the viscosity of water (continuous phase). The median diameters of the TO droplets in the EF-TO/W emulsions immediately after preparation between 40 and $60^{\circ} \mathrm{C}$ were slightly smaller than those prepared from 15 to $35^{\circ} \mathrm{C}$ (see Fig. 4a). On the other hand, the changes in the TO droplet size distribution and median diameter in the EF-TO/W emulsions over $7 \mathrm{~d}$ after preparation at temperatures between 15 and $60^{\circ} \mathrm{C}$ were similar (see Figs. S2 and S3). Therefore, the smaller median diameters of the TO droplets in the EF-TO/W emulsion immediately after preparation at $40-60^{\circ} \mathrm{C}$ compared to those prepared at $15-35^{\circ} \mathrm{C}$ did not affect the increase in the colloidal stability of the EF-TO/W emulsions on storage at temperatures from 25 to $40^{\circ} \mathrm{C}$ or the high colloidal stability of the EF-TO/W emulsion above $40^{\circ} \mathrm{C}$. In addition, the density difference between water and TO remained unchanged with increase in storage temperature (see Fig. 4b). That is, the increase in the colloidal stability of the EF-TO/W emulsion with increase in storage temperature from 25 to $40^{\circ} \mathrm{C}$ and high colloidal stability of EF-TO/W emulsion above $40^{\circ} \mathrm{C}$ cannot be attributed to changes in the density of TO with temperature.

Next, the effect of the repulsive electrostatic interactions between TO droplets (i.e., the zeta potential of the oil droplets) on the colloidal stability of the EF-TO/W emulsions was examined to elucidate the mechanism of the increase in the colloidal stability of the EF-TO/W emulsions at storage temperatures between 25 and $40^{\circ} \mathrm{C}$. The repulsive electrostatic interactions between oil droplets in $\mathrm{O} / \mathrm{W}$ emulsions can be explained by Derjaguin-Landau-VerweyOverbeek (DLVO) theory ${ }^{30-34)}$. This theory postulates that the colloidal stability of $\mathrm{O} / \mathrm{W}$ emulsions is controlled by the 
(a)

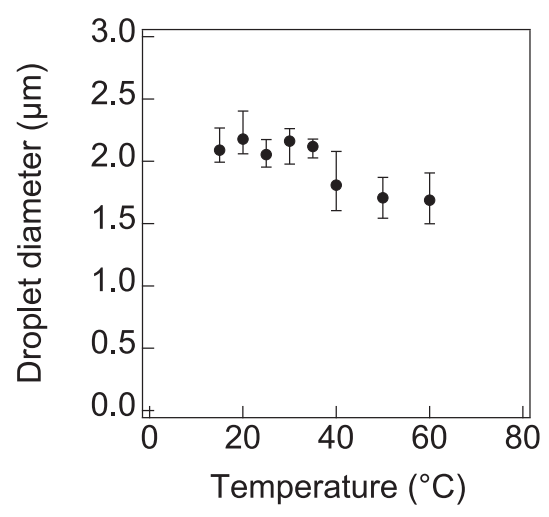

(c)

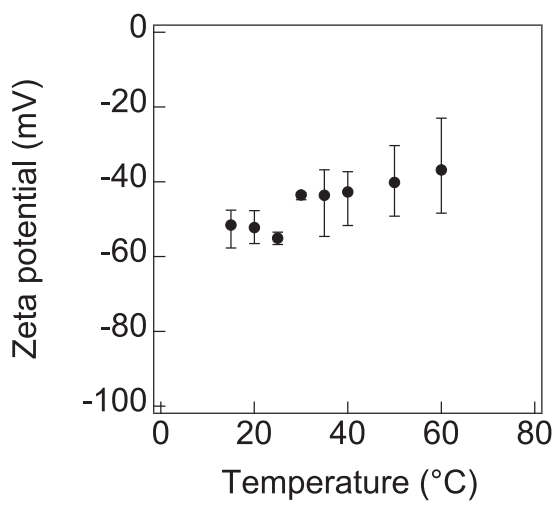

(b)

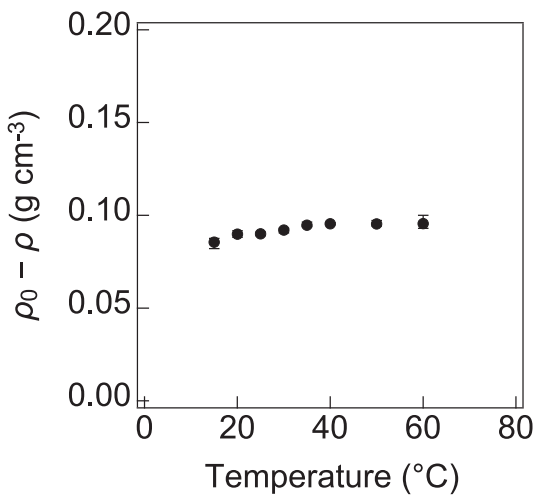

(d)

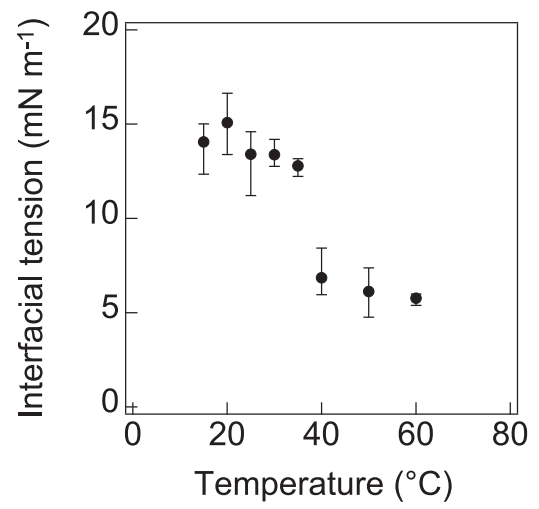

Fig. 4 (a) Median diameter of TO droplets in EF-TO/W emulsions right after preparation, (b) Density difference between water and TO $\left(\rho_{0}-\rho\right)$, (c) zeta-potential of TO droplets in EF-TO/W emulsions right after preparation and (d) interfacial tension between TO and water at 15, 20, 25, 30, 35, 40, 50 and $60^{\circ} \mathrm{C}$. Plot represents average value, and error bar represents the minimum and maximum in each measurement ( 3 times).

balance of attractive $\left(V_{\mathrm{A}}\right)$ and repulsive $\left(V_{\mathrm{R}}\right.$, see Eqs. 2 and $3)$ interactions between oil droplets in $\mathrm{O} / \mathrm{W}$ emulsions. In particular, the repulsive interaction $\left(V_{\mathrm{R}}\right)$ between oil droplets in $\mathrm{O} / \mathrm{W}$ emulsions is the dominant factor controlling the colloidal stability of $\mathrm{O} / \mathrm{W}$ emulsions.

$$
\begin{aligned}
& V_{\mathrm{R}}=\frac{\varepsilon r \zeta^{2}}{2} e^{-\kappa H} \\
& \kappa=\sqrt{\frac{8 \pi J F^{2}}{1000 \varepsilon R T}}
\end{aligned}
$$

Here, $r(\mathrm{~m})$ is the radius of the oil droplets, $\varepsilon\left(\mathrm{F} \mathrm{m}^{-1}\right)$ is the dielectric constant of the oil(dispersed phase), $\zeta(\mathrm{V})$ is the zeta potential of the oil droplets, $H(\mathrm{~m})$ is the distance between the oil droplets, $F\left(\mathrm{C} \mathrm{mol}^{-1}\right)$ is the Faraday constant, $J\left(\mathrm{~mol} \mathrm{~m}^{-3}\right)$ is the ionic strength, $R\left(\mathrm{~J} \mathrm{~mol}^{-1} \mathrm{~K}^{-1}\right)$ is the gas constant, and $T(\mathrm{~K})$ is the absolute temperature. $\kappa$ $\left(\mathrm{m}^{-1}\right)$ is the Debye-Hückel parameter (Eq. 3), and the reciprocal of the Debye-Hückel parameter $\left(\kappa^{-1}\right)$ represents the screening length of the electrical double-layer ${ }^{35,36)}$. Therefore, the stability of the $\mathrm{O} / \mathrm{W}$ emulsion increases with increase in the repulsive interaction $\left(V_{\mathrm{R}}\right)$ between oil droplets. Crucially, the $\mathrm{O} / \mathrm{W}$ interface acquires a negative charge even in the absence of emulsifiers such as surfactants ${ }^{37)}$. Therefore, the oil droplets in EF-O/W emulsions typically have a negative surface potential (zeta potential) ranging from 30 to $60 \mathrm{mV}^{7,9-11,17)}$. The TO droplets in the EF-TO/W emulsion also have a negative zeta potential, ranging from 30 to $60 \mathrm{mV}$ (see Fig. 4c). This surface charge of the oil droplets in the EF-O/W emulsion originates from the adsorption of hydroxide ions $\left(\mathrm{OH}^{-}\right)$in water onto the surfaces of the oil droplets, as confirmed by measurements of the change in the surface charge of oil droplets in EF-O/W emulsions as a function of $\mathrm{pH}^{38-40)}$. The measured zeta potential of the TO droplets in the EF-TO/W emulsions gradually decreased with increase in temperature (see Fig. 4c), whereas the colloidal stability of the EF-TO/W emulsions increased with temperature from 25 to $40^{\circ} \mathrm{C}$ and was maintained above $40^{\circ} \mathrm{C}$. Thus, the repulsive electrostatic interactions between TO droplets in the EF-TO/W emulsion is not the origin of the increase in their colloidal stability on increase in storage temperature between 25 or $40^{\circ} \mathrm{C}$ and their high colloidal stability above $40^{\circ} \mathrm{C}$.

Finally, the mechanism of the increase in the colloidal 
stability of the EF-TO/W emulsions between 25 to $40^{\circ} \mathrm{C}$ was examined in terms of the interfacial free energy $(G)$, that is, the interfacial tension $(\gamma)$ between TO and water. Because emulsions are a transient mixture of two immiscible liquids such as oil and water, they have high free energies (that is, interfacial free energies) $(G)$ at the $\mathrm{O} / \mathrm{W}$ interface $^{1-3)} . G$ is given by Eq. 4 .

$$
G=\gamma A
$$

Here, $\gamma\left(\mathrm{mN} \mathrm{m}^{-1}\right)$ is the interfacial tension between oil and water, and $A\left(\mathrm{~m}^{2}\right)$ is the area of the $\mathrm{O} / \mathrm{W}$ interface. Emulsions are typically prepared using emulsifiers, such as surfactants, because these compounds decrease the value of $\gamma$ between the oil and water phases, resulting in a decrease in $G$. As shown in Fig. 4d, the value of $\gamma$ between TO and water dramatically decreases as the temperature is increased from 35 to $40^{\circ} \mathrm{C}$. In contrast, the values of $\gamma$ for dodecane and water and for hexadecane and water do not change significantly between 15 and $60^{\circ} \mathrm{C}$ (see Fig. S4), suggesting that the colloidal stability of the EF-TO/W emulsions increases with increase in temperature from 25 to $40^{\circ} \mathrm{C}$ and that the high colloidal stability $40^{\circ} \mathrm{C}$ is a result of the decrease in $\gamma$ and, thus, $G$ between TO and water. The decrease in $\gamma$ between TO and water between 35 and $40^{\circ} \mathrm{C}$ can be attributed to the structural transformation of short-range ordered domains (clusters) of TO molecules in the liquid state. Generally, short-range ordered domains (clusters) of TGs exist even in their liquid states, and the structures of these clusters change with temperature ${ }^{41-46)}$. For example, deuterated trilaurin forms a nematic-like cluster structure in the liquid state ${ }^{41}$. In addition, TGs form a labile paralamellae-like (smectic phase) structure rather than a nematic-like structure in the liquid state ${ }^{42-45)}$. Moreover, Y-shaped TGs having three alkyl chains spread at $120^{\circ}$ can form a cylindrical symmetrically overlapping "discotic phase ${ }^{146)}$. This suggests that the transformation of the clusters of TO molecules in the liquid state of TO around $35-40^{\circ} \mathrm{C}$ results in a decrease in $\gamma$ between TO and water on increasing the temperature and, thus, an increase the colloidal stability of the EF-TO/W emulsions above $40^{\circ} \mathrm{C}$.

Next, we discuss the colloidal stability of the EF-TO/W emulsions at temperatures from 25 to $40^{\circ} \mathrm{C}$ and their high colloidal stability above $40^{\circ} \mathrm{C}$ with respect to Ostwald ripening, that is, the process by which oil molecules diffuse from smaller droplets to larger droplets in water (as defined by Kelvin's law). As shown by Lifshitz-Slyozov-Wagner (LSW) theory (Eq. 5) ${ }^{47,48)}$, an increase in temperature should promote Ostwald ripening because of the increase in the solubility of oil in water and the resulting demulsification of the EF-TO/W emulsion.

$$
\begin{aligned}
& \omega_{\text {Ostwald }}=\frac{\mathrm{d} r^{3}}{\mathrm{~d} t}=\frac{8 D c_{\infty} \gamma V_{m}^{2}}{9 R T} \\
& \text { Here, } \omega_{\text {Ostwald }}\left(=\mathrm{d} r^{3} / \mathrm{d} t\right)\left(\mathrm{m}^{3} \mathrm{~s}^{-1}\right) \text { is the growth rate of the }
\end{aligned}
$$

oil droplets, $r(\mathrm{~m})$ is the radius of the oil droplets, $t(\mathrm{~s})$ is the time, $D\left(\mathrm{~m}^{2} \mathrm{~s}^{-1}\right)$ is the diffusion constant of oil molecules in water, $c_{\infty}\left(\mathrm{mol} \mathrm{m}^{-3}\right)$ is the solubility of oil in water, $\gamma\left(\mathrm{N} \mathrm{m}^{-1}\right)$ is the interfacial tension between oil and water, $V_{m}\left(\mathrm{~m}^{3} \mathrm{~mol}^{-1}\right)$ is the molar volume of the oil, $R\left(\mathrm{~J} \mathrm{~mol}^{-1} \mathrm{~K}^{-1}\right)$ is the gas constant, and $T(\mathrm{~K})$ is the absolute temperature. As mentioned, Ostwald ripening between TO droplets in EF-TO/W emulsions should be favored by an increase in temperature because the solubility of TO in water increases with increasing temperature. As a result, the colloidal stability of EF-TO/W emulsions should decrease with increase in temperature. However, we observed the opposite trend; that is, an increase in colloidal stability at temperatures higher than $40^{\circ} \mathrm{C}$. This indicates that the increase in the colloidal stability of the EF-TO/W emulsions as the temperature increased from 25 to $40^{\circ} \mathrm{C}$ and their high colloidal stability above $40^{\circ} \mathrm{C}$ are not attributed to Ostwald ripening. Furthermore, the changes in the size distribution of TO droplets in the EF-TO/W emulsions prepared at 15, 20, 25, 30, $35,40,50$, and $60^{\circ} \mathrm{C}$ with time showed no significant changes over $7 \mathrm{~d}$ after preparation(see Fig. S2). The median diameters of the TO droplets in the EF-TO/W emulsions prepared at $15,20,25,30,35,40,50$, and $60^{\circ} \mathrm{C}$ decreased from approximately 2.2 to $1.3 \mu \mathrm{m}$ over $7 \mathrm{~d}$ from preparation (see Fig. S3). The decrease in the median diameter of the TO droplets in the EF-TO/W emulsions with time after preparation is likely due to the floating of larger TO droplets. The trend in the decrease in the median diameter of TO droplets in the EF-TO/W emulsions is similar between 15 and $60^{\circ} \mathrm{C}$ (see Fig. S3). These results also indicate that the increase in the colloidal stability of the EF-TO/W emulsions with increase in temperature from 25 to $40^{\circ} \mathrm{C}$ and high colloidal stability of EF-TO/W emulsions above $40^{\circ} \mathrm{C}$ are not attributed to Ostwald ripening.

\section{Conclusions}

The colloidal stability of emulsifier-free triolein-in-water (EF-TO/W) emulsions decreases with increase in temperature from 15 to $25^{\circ} \mathrm{C}$, whereas the colloidal stability of these emulsions increases as the preparation and storage temperatures increase from 25 to $40^{\circ} \mathrm{C}$. The increase in the colloidal stability of the EF-TO/W emulsions as the preparation and storage temperatures increased from 25 to $40^{\circ} \mathrm{C}$ likely results from the decrease in interfacial tension $(\gamma)$ between $\mathrm{TO}$ and water resulting from the transformation of short-range ordered domains (clusters) of TO molecules in the liquid state of $\mathrm{TO}$ around $35-40^{\circ} \mathrm{C}$. This result suggests that the internal state of the oil droplets in $\mathrm{O} / \mathrm{W}$ emulsions affects the interfacial state, and, simultaneously, the interfacial state affects the colloidal stability of the emulsion. 


\section{K. Takei, M. Watanabe, K. Kawasaki et al.}

\section{Supporting Information}

This material is available free of charge via the Internet at doi: 10.5650/jos.ess21234

\section{References}

1) Friberg, S.E.; Larsson, K.; Sjöblom, J. Food emulsions ( $4^{\text {th }}$ ed.). Marcel Dekker, New York (2004).

2) McClements, D.J. Food emulsions: Principles, practices, and techniques ( $2^{\text {nd }}$ ed.), CRC Press, Boca Raton (2005).

3) Sarker, D.K. Pharmaceutical Emulsions. WILEY Blackwell, Oxford (2013).

4) Kamogawa, K.; Sakai, T.; Momozawa, N.; Shimazaki, M.; Enomura, M. et al. Evolution and growth of oil droplets in emulsifier-free, metastable aqueous solutions: A light scattering and conductive probe study. J. Jpn. Oil Chem. Soc. 47, 159-170(1998).

5) Kamogawa, K.; Matsumoto, M.; Kobayashi, T.; Sakai, T.; Sakai, H.; Abe, M. Dispersion and stabilizing effects of $n$-hexadecane on tetralin and benzene metastable droplets in surfactant-free conditions. Langmuir 15, 1913-1917 (1999).

6) Kamogawa, K.; Akatsuka, H.; Matsumoto, M.; Yokoyama, S.; Sakai, T. et al. Surfactant-free O/W emulsion formation of oleic acid and its esters with ultrasonic dispersion. Colloids Surf. A 180, 41-53 (2001).

7) Sakai, T.; Kamogawa, K.; Harusawa, F.; Momozawa, N.; Sakai, H.; Abe, M. Direct observation of flocculation/ coalescence of metastable oil droplets in surfactantfree oil/water emulsion by freeze-fracture electron microscopy. Langmuir 17, 255-259 (2001).

8) Sakai, T.; Kamogawa, K.; Nishiyama, K.; Sakai, H.; Abe, M. Molecular diffusion of oil/water emulsions in surfactant-free conditions. Langmuir 18, 1985-1990 (2002).

9) Kamogawa, K.; Kuwayama, N.; Katagiri, T.; Akatsuka, H.; Sakai, T. et al. Dispersion and stabilization in water of droplets of hydrophobic organic liquids with the addition of hydrophobic polymers. Langmuir 19, 40634069 (2003).

10) Sakai, T.; Takeda, Y.; Mafune, F.; Abe, M.; Kondow, T. Monitoring growth of surfactant-free nanodroplets dispersed in water by single-droplet detection. J. Phys. Chem. B 107, 2921-2926(2003).

11) Sakai, T.; Takeda, Y.; Mafune, F.; Kondow, T. Surface properties of surfactant-free oil droplets dispersed in water studied by confocal fluorescence microscopy. $J$. Phys. Chem. B 108, 6359-6364(2004).

12) Kamogawa, K.; Okudaira, G.; Matsumoto, M.; Sakai, T.; Sakai, H.; Abe, M. Preparation of oleic acid/water emulsions in surfactant-free condition by sequential processing using midsonic-megasonic waves. Langmuir 20, 2043-2047 (2004).
13) Sakai, T. Surfactant-free emulsions. Curr. Opin. Colloid Interf. Sci. 13, 228-235(2008).

14) Sakai, T.; Seo, K. Colloidal stability of emulsifier-free water-in-oil emulsions: Effect of oil property. J. Jpn. Soc. Colour Mater. 87, 387-392 (2014).

15) Sakai, T.; Urabe, S.; Seo, K. Emulsifier-free water-in-oil emulsions: Colloidal stabilization by vegetable oil. $J$. Jpn. Soc. Colour Mater. 89, 333-339(2016).

16) Sakai, T.; Oishi, T. Colloidal stabilization of surfactantfree emulsion by control of molecular diffusion among droplets. J. Taiwan Inst. Chem. Eng. 92, 123-128 (2018).

17) Pashley, R.M. Effect of degassing on the formation and stability of surfactant-free emulsions and fine teflon dispersions. J. Phys. Chem. B 107, 1714-1720(2003).

18) Maeda, N.; Rosenberg, K.J.; Israelachvili, J.N.; Pashley, R.M. Further studies on the effect of degassing on the dispersion and stability of surfactant-free emulsions. Langmuir 20, 3129-3137 (2004).

19) Francis, M.J.; Pashley, R.M. A study of de-gassed oil in water dispersions as potential drug delivery systems. Colloids Surf. A 260, 7-16(2005).

20) Nakabayashi, K.; Amemiya, F.; Fuchigami, T.; Machida, K.; Takeda, S. et al. Highly clear and transparent nanoemulsion preparation under surfactant-free conditions using tandem acoustic emulsification. Chem. Commun. 47, 5765-5767(2011).

21) Nakabayashi, K.; Fuchigami, T.; Atobe, M. Tandem acoustic emulsion, an effective tool for the electrosynthesis of highly transparent and conductive polymer films. Electrochimica Acta 110, 593-598(2013).

22) Nakabayashi, K.; Kojima, M.; Inagi, S.; Hirai, Y.; Atobe, M. Size-controlled synthesis of polymer nanoparticles with tandem acoustic emulsification followed by soapfree emulsion polymerization. ACS Macro Lett. 2, 482484 (2013).

23) Nakabayashi, K.; Fuchigami, T.; Atobe, M. Templated electrochemical synthesis of conducting polymer nanowires from corresponding monomer nanoemulsions prepared by tandem acoustic emulsification. RSC Adv. 4, 22938-22940 (2014).

24) Nakabayashi, K.; Yanagi, H.; Atobe, M. Preparation of W/O nanoemulsion using tandem acoustic emulsification and its novel utilization as a medium for phasetransfer catalytic reaction. $R S C A d v .4,57608-57610$ (2014).

25) Kumpugdee-Vollrath, M.; Krause, J.-P.; Bürk, S. Surfactant-free $\mathrm{O} / \mathrm{W}$-emulsion as drug delivery system. Inter. J. Pharmacological Pharmaceutical Sci. 8, 574-577 (2014).

26) McClements, D.J.; Gumus, C.E. Natural emulsifiers Biosurfactants, phospholipids, biopolymers, and colloidal particles: Molecular and physicochemical basis of functional performance. Adv. Colloid Interface Sci. 
234, 3-26 (2016).

27) McClements, D.J.; Jafari, S.M. Improving emulsion formation, stability and performance using mixed emulsifiers: A review. Adv. Colloid Interface Sci. 251, 55-79 (2018).

28) Kim, W.; Wang, Y.; Selomulya, C. Dairy and plant proteins as natural food emulsifiers. Trends Food Sci. Technol. 105, 261-272(2020).

29) Evans, D.F.; Wennerstrom, H. THE COLLOIDAL DOMAIN Where Physics, Chemistry, Biology, and Technology Meet ( $2^{\text {nd }}$ ed.), WILEY-VCH, New York (1999).

30) Derjaguin, B.V.; Landau, L.D. Theory of the stability of strongly charged lyophobic sols and of the adhesion of strongly charged particles in solutions of electrolytes. Acta Physicochim. URSS 14, 633-662(1941).

31) Verwey, E.J.W. Theory of the stability of lyophobic colloids. J. Phys. Chem. 51, 631-636(1947).

32) Verwey, E.J.W.; Overbeek, J.T.G. Theory of the Stability of Lyophobic Colloids. Elsevier, Amsterdam (1948).

33) Reerink, H.; Overbeek, J.T.G. The rate of coagulation as a measure of the stability of silver iodide sols. Discuss. Faraday Soc. 18, 74-84(1954).

34) Derjaguin, B.V.; Churaev, N.V.; Muller, V.M. Surface Forces. Springer Science+Business Media, New York (1987).

35) Kerker, M. Colloid and Interface Science. Academic Press, New York, p. 529 (1976).

36) Buscall, R.; Goodwin, J.W.; Hawkins, M.W.; Ottewill, R.H. J. Chem. Soc. Faraday Trans. 78, 2889 (1982).

37) Taylor, A.J.; Wood, F.W. Electrophoresis of hydrocarbon droplets in dilute solutions of electrolytes. Trans. Faraday Soc. 53, 523-529(1957).

38) Marinova, K.G.; Alargova, R.G.; Denkov, N.D.; Velev, O.D.; Petsev, D.N. et al. Charging of oil-water interfaces due to spontaneous adsorption of hydroxyl ions.
Langmuir 12, 2045-2051 (1996).

39) Stachurski, J.; Michalek, M. The effect of the z potential on the stability of a non-polar oil-in-water emulsion. J. Colloid Interface Sci. 184, 433-436 (1996).

40) Beattie, J.K.; Djerdjev, A.M. The pristine oil/water interface: Surfactant-free hydroxide-charged emulsions. Angew. Chem. Int. Ed. 43, 3568-3571(2004).

41) Cebula, D.J.; Mcclements, D.J.; Povey, M.J.W.; Smith, P.R. Neutron-diffraction studies of liquid and crystalline trilaurin. J. Am. Oil Chem. Soc. 69, 130-136 (1992).

42) Larsson, K. Molecular arrangement in glycerides. Eur. J. Lipid Sci. Technol. 74, 136-142(1972).

43) Hernqvist, L.; Larsson, K. On the crystal structure of the $\beta^{\prime}$-form of triglycerides and structural changes at the phase transitions LIQ. $\rightarrow \alpha \rightarrow \beta^{\prime} \rightarrow \beta$. Eur. J. Lipid Sci. Technol. 84, 349-354(1982).

44) Hernqvist, L. On the structure of triglycerides in the lipquid state and fat crystallization. Eur. J. Lipid Sci. Technol. 86, 297-300 (1984).

45) Larsson, K. On the structure of the liquid-state of triglycerides. J. Am. Oil Chem. Soc. 69, 835-836(1992).

46) Corkery, R.W.; Rousseau, D.; Smith, P.; Pink, D.A.; Hanna, C.B. A case for discotic liquid crystals in molten triglycerides. Langmuir 23, 7241-7246 (2007).

47) Lifshitz, I.M.; Slezov, V.V. Sov. Phys. JETP 8, 331 (1959).

48) Wagner, C. Theory of precipitate change by redissolution. Z. Elektochem. 35, 581-591 (1961).

CC BY 4.0 (Attribution 4.0 International). This license allows users to share and adapt an article, even commercially, as long as appropriate credit is given. That is, this license lets others copy, distribute, remix, and build upon the Article, even commercially, provided the original source and Authors are credited. 